ARTICLE

DOI: $10.1038 / s 41467-018-04060-8$

\title{
Aqueous rechargeable zinc/sodium vanadate batteries with enhanced performance from simultaneous insertion of dual carriers
}

\author{
Fang Wan ${ }^{1}$, Linlin Zhang ${ }^{1}$, Xi Dai ${ }^{1}$, Xinyu Wang ${ }^{1}$, Zhiqiang Niu ${ }^{1} \&$ Jun Chen ${ }^{1,2}$
}

Rechargeable aqueous zinc-ion batteries are promising energy storage devices due to their high safety and low cost. However, they remain in their infancy because of the limited choice of positive electrodes with high capacity and satisfactory cycling performance. Furthermore, their energy storage mechanisms are not well established yet. Here we report a highly reversible zinc/sodium vanadate system, where sodium vanadate hydrate nanobelts serve as positive electrode and zinc sulfate aqueous solution with sodium sulfate additive is used as electrolyte. Different from conventional energy release/storage in zinc-ion batteries with only zinc-ion insertion/extraction, zinc/sodium vanadate hydrate batteries possess a simultaneous proton, and zinc-ion insertion/extraction process that is mainly responsible for their excellent performance, such as a high reversible capacity of $380 \mathrm{mAh} \mathrm{g}^{-1}$ and capacity retention of $82 \%$ over 1000 cycles. Moreover, the quasi-solid-state zinc/sodium vanadate hydrate battery is also a good candidate for flexible energy storage device.

\footnotetext{
${ }^{1}$ Key Laboratory of Advanced Energy Materials Chemistry (Ministry of Education), College of Chemistry, Nankai University, Tianjin 300071, P. R. China. ${ }^{2}$ Collaborative Innovation Center of Chemical Science and Engineering, Nankai University, Tianjin 300071, P. R. China. Correspondence and requests for materials should be addressed to Z.N. (email: zqniu@nankai.edu.cn)
} 
ithium-ion batteries have been widely used in portable electronics and considered for electric vehicles, as well as large-scale energy storage systems due to their high energy density ${ }^{1,2}$. However, the increasing concerns about cost, safety, the limited lithium resources as well as environmental impact motivate the search of alternative battery systems ${ }^{3-5}$. In this regard, rechargeable aqueous batteries are the promising alternatives since the utilization of aqueous electrolytes will contribute to better safety, lower cost, easier processing, and higher ionic conductivity compared with the case of organic electrolytes ${ }^{6-8}$. Among various aqueous batteries, there is a growing interest in aqueous $\mathrm{Zn}$-ion batteries (ZIBs) due to the distinctive merits of $\mathrm{Zn}$, in terms of high theoretical capacity $\left(820 \mathrm{mAh} \mathrm{g}^{-1}\right)$, low redox potential $(-0.76 \mathrm{~V}$ vs. standard hydrogen electrode), excellent stability in water, and nontoxicity ${ }^{9-14}$.

Recently, significant research efforts have been made in designing the materials and devices of aqueous $\mathrm{ZIBs}^{15-32}$. However, aqueous ZIBs are still in their infancy and there are still some challenges, which limit the practical application of aqueous ZIBs. For instance, although some active materials such as $\mathrm{MnO}_{2}{ }^{20-24}, \mathrm{Mo}_{6} \mathrm{~S}_{8}{ }^{29,30}$, prussian blue analogs ${ }^{25-28}$, $\mathrm{Na}_{3} \mathrm{~V}_{2}\left(\mathrm{PO}_{4}\right)_{3}{ }^{31}$, and vanadium-based compounds ${ }^{16-18}$ have been fabricated as the positive electrodes of aqueous ZIBs, most of them often exhibit limited capacity of less than $300 \mathrm{mAh} \mathrm{g}^{-1}$ and/ or poor cycling performance. In addition, the conventional energy release/storage mechanism of ZIBs is the insertion/ extraction of $\mathrm{Zn}^{2+}$ in the host materials ${ }^{16-18,31,33}$. However, in some cases of $\mathrm{Zn} / \mathrm{MnO}_{2}$ system, the chemical conversion reaction between $\mathrm{MnO}_{2}$ and $\mathrm{H}^{+}$can also mainly contribute to the good electrochemical performance of the highly reversible $\mathrm{Zn} / \mathrm{MnO}_{2}$ system ${ }^{24}$. Both different mechanisms in $\mathrm{MnO}_{2}$ positive electrodes may be attributed to their variety in crystallographic polymorph and particle size, which are dependent on the ion insertion thermodynamics and kinetics of $\mathrm{H}^{+}$and $\mathrm{Zn}^{2+}$. As a result, $\mathrm{H}^{+}$ and $\mathrm{Zn}^{2+}$ cannot simultaneously insert into $\mathrm{MnO}_{2}$ and their insertion is often a two-step process, where $\mathrm{H}^{+}$first inserts into $\mathrm{MnO}_{2}$ and then $\mathrm{Zn}^{2+34}$. Compared with a consequent insertion process, simultaneous insertion of dual carriers would achieve enhanced synergistic effect of their ion insertion thermodynamics and kinetics 35,36 . Therefore, the feasible host materials that are able to carry out a simultaneous $\mathrm{H}^{+}$and $\mathrm{Zn}^{2+}$ insertion/ extraction process with enhanced performance should be considered and developed.

Owing to the low cost and multivalence of vanadium, vanadates have been utilized as the positive electrodes of lithium/ sodium-ion batteries ${ }^{37-41}$. As one of promising positive electrodes, $\mathrm{NaV}_{3} \mathrm{O}_{8}$ is composed of $\mathrm{V}_{3} \mathrm{O}_{8}$ layers and inserted sodium ions $^{39}$. More importantly, the interlayer distance $(0.708 \mathrm{~nm})$ of $\mathrm{NaV}_{3} \mathrm{O}_{8}$ would be large enough to enable the insertion/extraction of $\mathrm{Zn}^{2+}(0.074 \mathrm{~nm})$, and $\mathrm{H}^{+}$could steadily exist between the $\mathrm{V}_{3} \mathrm{O}_{8}$ layers ${ }^{42,43}$. Therefore, the nanostructured $\mathrm{NaV}_{3} \mathrm{O}_{8}$ would be an ideal positive electrodes of aqueous rechargeable $\mathrm{ZIB}$ with a simultaneous $\mathrm{H}^{+}$and $\mathrm{Zn}^{2+}$ insertion/extraction process.

Here we fabricate $\mathrm{NaV}_{3} \mathrm{O}_{8} \cdot 1.5 \mathrm{H}_{2} \mathrm{O}$ (NVO) nanobelts by a simple liquid-solid stirring strategy. The interlayer water and sodium ions could act as pillars to stabilize the $\mathrm{V}_{3} \mathrm{O}_{8}$ layers during the charge/discharge process. As the positive electrodes for aqueous ZIBs, they exhibit a simultaneous $\mathrm{H}^{+}$and $\mathrm{Zn}^{2+}$ insertion/ extraction process with a high reversible capacity of $380 \mathrm{mAh} \mathrm{g}^{-1}$ and enhanced cycling performance by the addition of $\mathrm{Na}_{2} \mathrm{SO}_{4}$ into the $\mathrm{ZnSO}_{4}$ electrolyte to inhibit the dissolution of $\mathrm{NVO}$ and Zn dendrite deposition synchronously. Furthermore, the nanobelt structure of NVO endows their corresponding positive electrodes with the ability of being bent without any cracks to serve as the electrodes of flexile ZIBs. As a proof of concept, flexible softpackaged ZIBs are assembled using quasi-solid-state electrolyte, exhibiting stable electrochemical performances at different bending states.

\section{Results}

Preparation and characterization of NVO nanobelts. NVO nanobelts were prepared through a facile liquid-solid stirring method, just stirring the $\mathrm{V}_{2} \mathrm{O}_{5}$ powder in $\mathrm{NaCl}$ aqueous solution (Methods section for details). With the increase of stirring time, the color of suspension changed from yellow to black red (Supplementary Fig. 1) due to the insertion of sodium ions into $\mathrm{V}_{x} \mathrm{O}_{y}$ layers and the formation of nanobelt morphology via a dissolution-recrystallization process ${ }^{44,45}$. The crystalline phase of as-prepared sample was tested by X-ray diffraction (XRD), as shown in Fig. 1a. Its characteristic peaks are in good agreement with $\mathrm{NVO}$ with $\mathrm{P} 2{ }_{1} / \mathrm{m}$ space group (JCPDS: 16-0601). In the $\mathrm{P} 2{ }_{1} /$
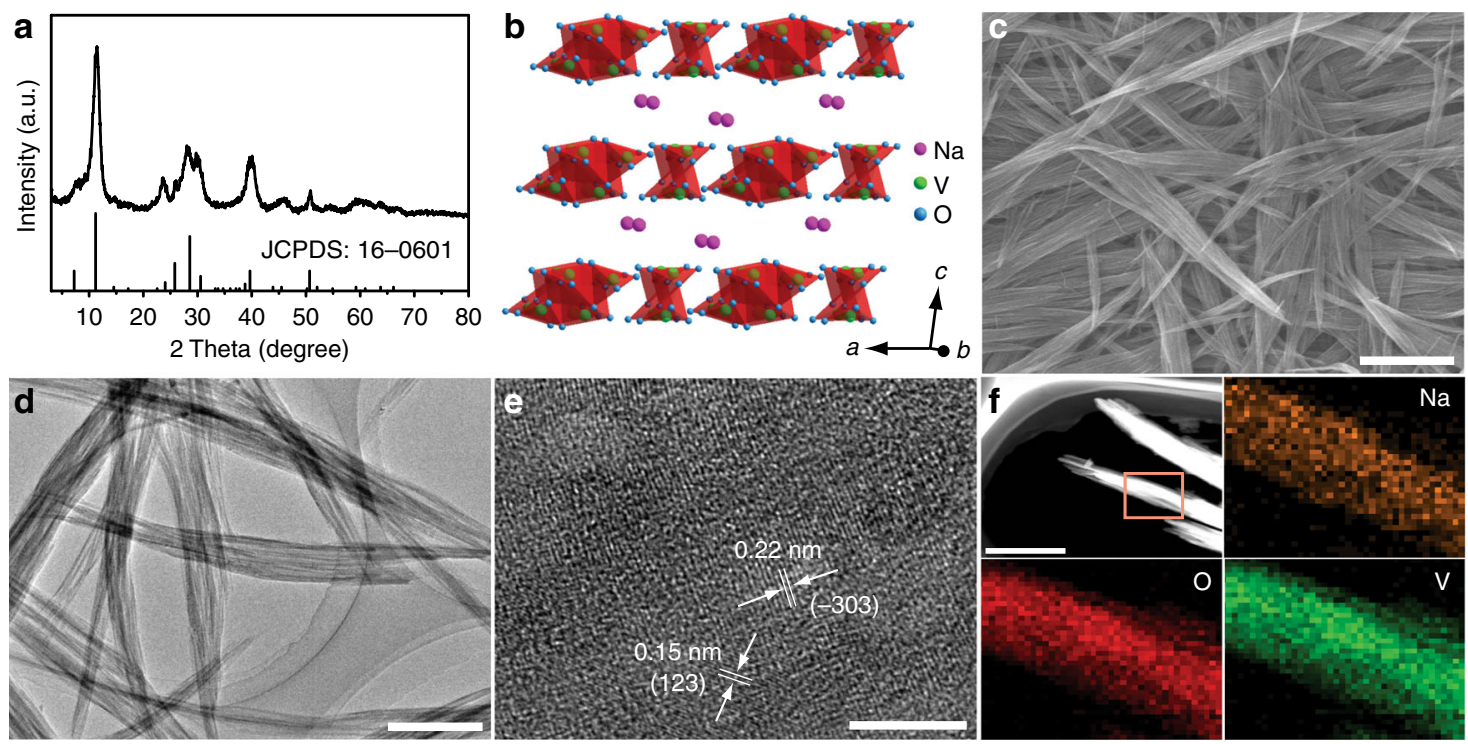

Fig. 1 Crystal structure and morphology of NVO. a XRD pattern of NVO nanobelts. b Crystal structure of NVO nanobelts, $\mathrm{Na}^{+}$exists in the form of hydrated ion. c SEM, d TEM, e high-resolution TEM, and f TEM elemental mapping images of NVO nanobelts. Scale bars of $1 \mu \mathrm{m}, 200,5$ and $400 \mathrm{~nm}$, respectively 

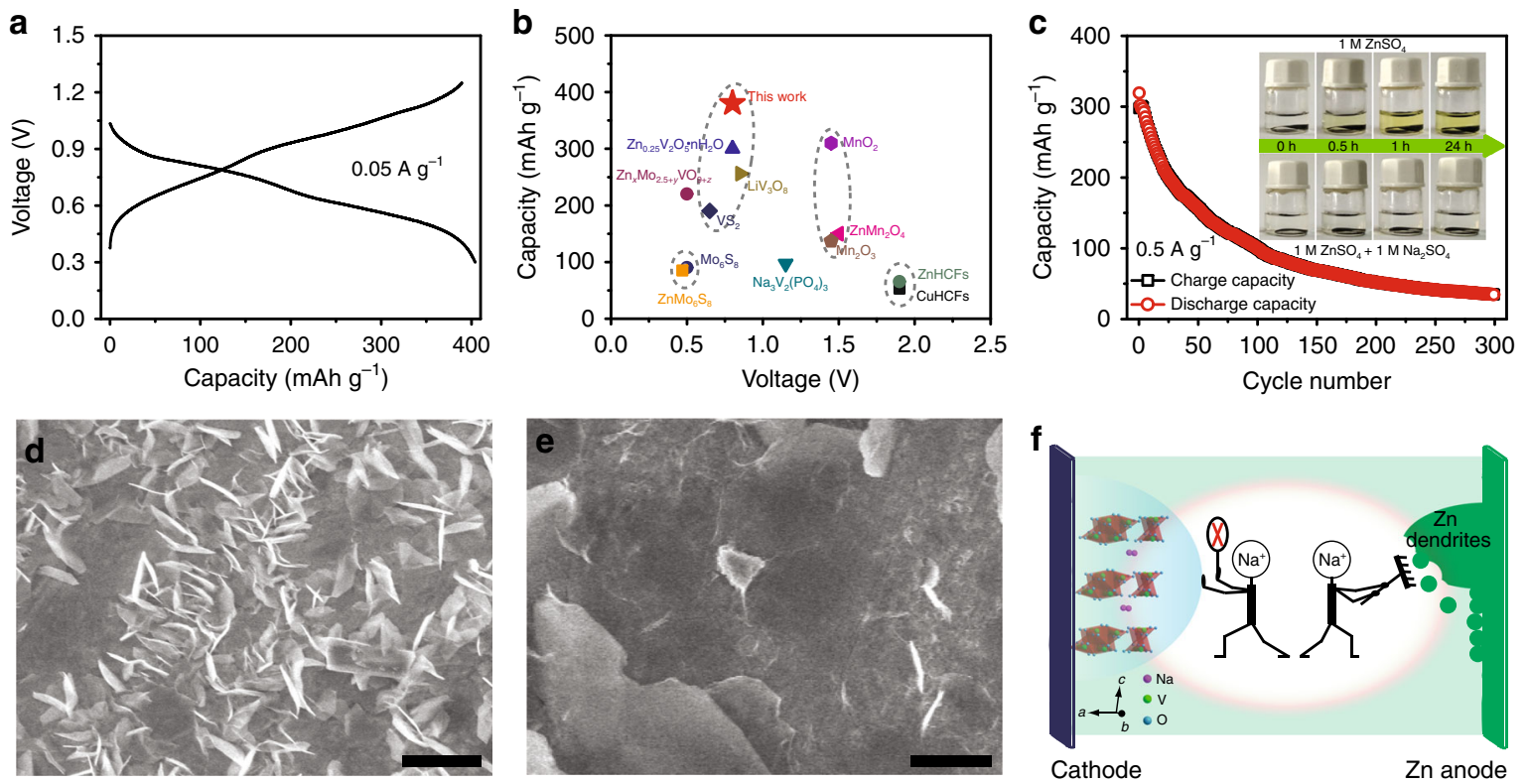

Fig. 2 Electrochemical performance of $\mathrm{Zn} / \mathrm{NVO}$ batteries in $1 \mathrm{M} \mathrm{ZnSO}_{4}$ electrolyte and function of $\mathrm{Na}_{2} \mathrm{SO}_{4}$ electrolyte additive. a First charge/discharge curve of $\mathrm{NVO}$ electrode in $\mathrm{ZnSO}_{4}$ electrolyte. $\mathbf{b}$ Comparison of reversible capacity and operating voltage between $\mathrm{NVO}$ nanobelts and other reported positive electrode materials. c Cycling performance of $\mathrm{NVO}$ electrode in $\mathrm{ZnSO}_{4}$ electrolyte. The insets are optical images of $\mathrm{NVO}$ electrodes in $\mathrm{ZnSO} \mathrm{H}_{4}$ and $\mathrm{ZnSO}_{4} / \mathrm{Na}_{2} \mathrm{SO}_{4}$ electrolytes for different periods. SEM images of the $\mathrm{Zn}$ negative electrode surface from $\mathrm{Zn} /$ steel mesh batteries after one $\mathrm{CV}$ cycle from -0.2 to $0.3 \mathrm{~V}$ in $\mathbf{d} \mathrm{ZnSO}_{4}$ and $\mathbf{e} \mathrm{ZnSO}_{4} / \mathrm{Na}_{2} \mathrm{SO}_{4}$ electrolytes. Scale bars, $2 \mu \mathrm{m}$. $\mathbf{f}$ Schematic diagram: $\mathrm{Na}_{2} \mathrm{SO}_{4}$ additive suppresses the dissolution of $\mathrm{NVO}$ nanobelts and the formation of $\mathrm{Zn}$ dendrites

$\mathrm{m}$ NVO, hydrated sodium ions, acting as pillars, are between the $\mathrm{V}_{3} \mathrm{O}_{8}$ layers to stabilize the layered structure, which consists of edge-sharing $\mathrm{VO}_{5}$ tetragonal pyramids and $\mathrm{VO}_{6}$ octahedrons, as depicted in Fig. 1b. Furthermore, obviously, the XRD pattern suggests the high purity of the as-prepared NVO, which can also be confirmed by combining its X-ray photoelectron spectroscopy (XPS) with Fourier transform infrared (FTIR) spectra (Supplementary Fig. 2). The XPS spectroscopy of the as-prepared NVO shows six peaks that all belong to $\mathrm{Na}, \mathrm{V}$, and $\mathrm{O}$ without other impure elements. In its FTIR spectra, absorption bands located at 968 and $999 \mathrm{~cm}^{-1}$ are assigned to stretching vibrations of $\mathrm{V}=\mathrm{O}$, while those at $545,732,1400$, and $1633 \mathrm{~cm}^{-1}$ are ascribed to symmetric and asymmetric stretching vibrations of $\mathrm{V}-\mathrm{O}-\mathrm{V}$ bonds, vibrations of $\mathrm{Na}-\mathrm{O}$ bonds as well as crystal water vibrations, respectively ${ }^{46-48}$.

Figure $1 \mathrm{c}$ and Supplementary Fig. 3 are the typical scanning electron microscopy (SEM) images of NVO, showing a homogeneous nanobelt morphology. They are tens of micrometers in length and 50-200 $\mathrm{nm}$ in width. Transmission electron microscopy (TEM) image also affirms their anisotropic and flat morphology with high aspect ratio, as well as their crystallinity (Fig. 1d, e). The interplanar spacings of 0.23 and $0.15 \mathrm{~nm}$, corresponding to $(-303)$ and (123) planes of NVO nanobelts, respectively, are observed in their high-resolution TEM image (Fig. 1e), which is well matched with the XRD result (Fig. 1a). In addition, the homogeneous distributions of $\mathrm{Na}, \mathrm{V}$, and $\mathrm{O}$ in $\mathrm{NVO}$ nanobelts were further evidenced by TEM elemental mapping images in Fig. 1f. Such favorable morphological features would be beneficial for the fast kinetics of the carrier insertion/extraction.

Electrochemical performance of NVO nanobelts. The electrochemical performances of NVO nanobelts as the positive electrodes of ZIBs were investigated in assembled coin cells. In contrast to traditional alkaline $\mathrm{Zn}$-based batteries with poor coulombic efficiency and fast capacity decay ${ }^{7}$, mild $1 \mathrm{M} \mathrm{ZnSO}_{4}$ aqueous solution was initially used as the electrolyte in our case. The NVO nanobelts deliver an average operating voltage of about $0.8 \mathrm{~V}$ vs. $\mathrm{Zn}^{2+} / \mathrm{Zn}$, as well as a high reversible capacity of 380 $\mathrm{mAh} \mathrm{g}^{-1}$ based on the mass of NVO in positive electrode in the first cycle at a current density of $0.05 \mathrm{Ag}^{-1}$ (Fig. 2a), which is higher than those of previously reported positive electrodes

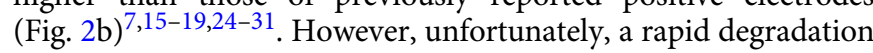
in capacity occurs with an increase in the cycle number, decaying to only $33 \mathrm{mAh} \mathrm{g}^{-1}$ after 300 cycles at a current density of $0.5 \mathrm{~A}$ $\mathrm{g}^{-1}$ (Fig. 2c). Such rapid capacity fading would be ascribed to the fast dissolution of $\mathrm{NVO}$ in the aqueous $\mathrm{ZnSO}_{4}$ electrolyte and the formation of vertical and harsh $\mathrm{Zn}$ dendrites, as suggested by the inset in Fig. 2c, d, respectively. The addition of $\mathrm{Na}^{+}$into the electrolyte can change the dissolution equilibrium of $\mathrm{Na}^{+}$from NVO electrodes and thus impede the continuous NVO dissolution. To confirm this, NVO electrodes were dipped into the $\mathrm{ZnSO}_{4}$ electrolytes with different concentrations of $\mathrm{Na}_{2} \mathrm{SO}_{4}$ (the inset in Fig. 2c and Supplementary Fig. 4). When the concentration of $\mathrm{Na}_{2} \mathrm{SO}_{4}$ is up to $1 \mathrm{M}$, the electrolyte would be transparent and colorless even when the NVO positive electrodes were in the electrolyte for $24 \mathrm{~h}$, indicating that the NVO dissolution was suppressed. Therefore, $1 \mathrm{M} \mathrm{Na}_{2} \mathrm{SO}_{4}$ was added into the $\mathrm{ZnSO}_{4}$ electrolyte as the electrolyte additive in our $\mathrm{Zn} / \mathrm{NVO}$ system. In addition, according to electrostatic shield mechanism, the dendrite deposition during charge process would be avoided by adding other positive ions with lower reduction potential into electrolyte ${ }^{49}$. Compared with $\mathrm{Zn}^{2+}, \mathrm{Na}^{+}$has a lower reduction potential. As a result, the addition of $\mathrm{Na}_{2} \mathrm{SO}_{4}$ in $\mathrm{ZnSO}_{4}$ electrolyte could effectively avoid the growth of $\mathrm{Zn}$ dendrites (Fig. 2e, Supplementary Figs 6 and 7) in comparison with the case of $\mathrm{ZnSO}_{4}$ electrolyte without $\mathrm{Na}_{2} \mathrm{SO}_{4}$, where a large number of vertical and harsh $\mathrm{Zn}$ dendrites formed on the surface of $\mathrm{Zn}$ negative electrode (Fig. 2d, Supplementary Figs 5 and 6). Therefore, the $\mathrm{Na}^{+}$from $\mathrm{Na}_{2} \mathrm{SO}_{4}$ not only can prevent the dissolution of $\mathrm{NVO}$, but also suppresses the $\mathrm{Zn}$ dendrite deposition, as depicted in Fig. $2 \mathrm{f}$. 

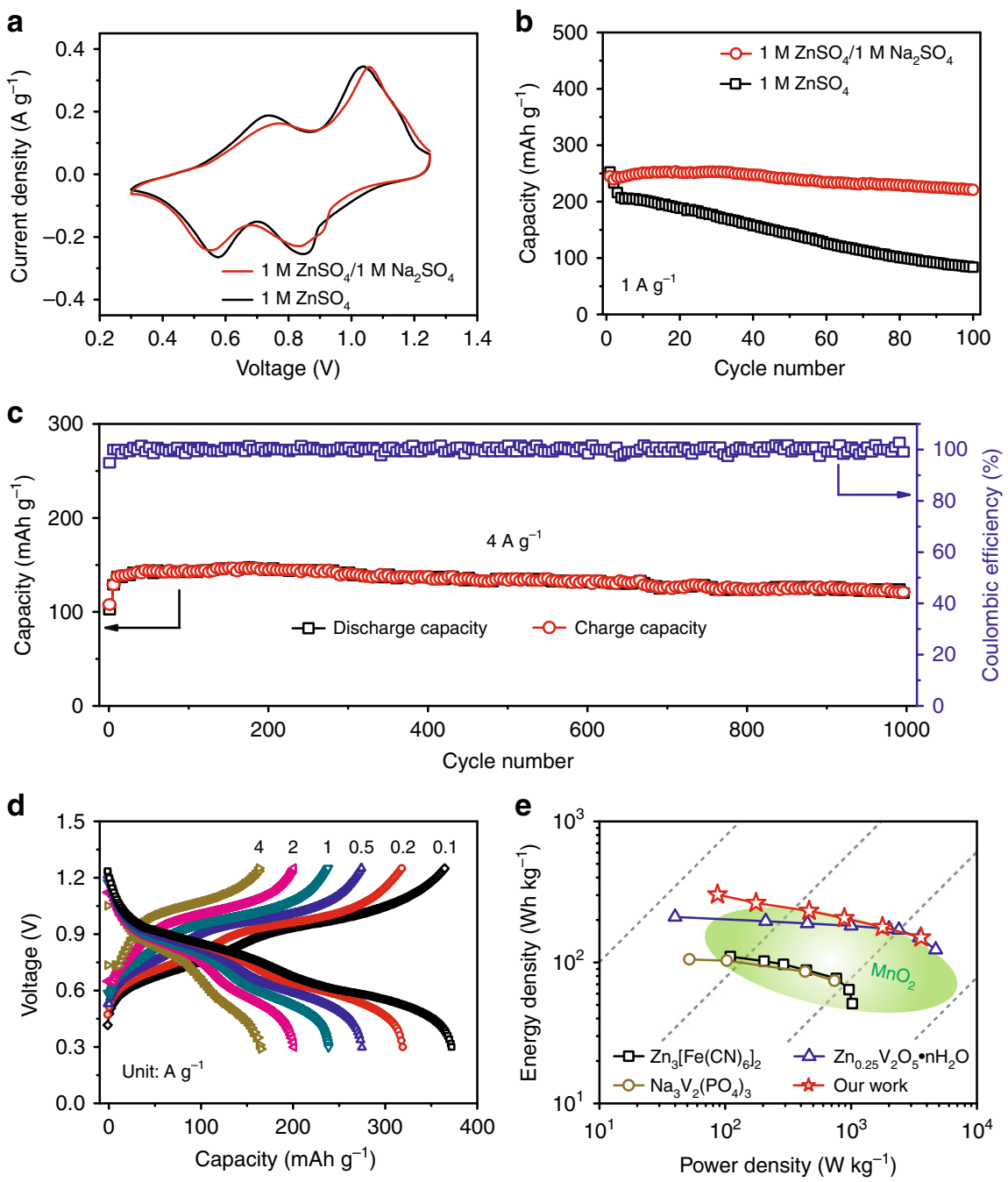

Fig. 3 Electrochemical performance of $\mathrm{Zn} / \mathrm{NVO}$ batteries in $1 \mathrm{M} \mathrm{ZnSO}_{4}$ electrolyte with $1 \mathrm{M} \mathrm{Na}_{2} \mathrm{SO}_{4}$ additive. Comparison of a second CV curves ( $0.1 \mathrm{mV}$ $\mathrm{s}^{-1}$ ) and $\mathbf{b}$ cycling performance $\left(1 \mathrm{~A} \mathrm{~g}^{-1}\right)$ of $\mathrm{NVO}$ electrodes in $\mathrm{ZnSO}_{4}$ and $\mathrm{ZnSO}_{4} / \mathrm{Na}_{2} \mathrm{SO}_{4}$ electrolytes. $\mathbf{c}$ Long-term cycle life $\left(4 \mathrm{Ag} \mathrm{g}^{-1}\right)$ and $\mathbf{d}$ rate performance of $\mathrm{NVO}$ electrodes in $\mathrm{ZnSO}_{4} / \mathrm{Na}_{2} \mathrm{SO}_{4}$ electrolyte. e Comparison of energy and power densities of $\mathrm{Zn} / \mathrm{NVO}$ battery with $\mathrm{ZIBs}$ based on reported positive electrodes

Figure 3 a compares the second cyclic voltammetly (CV) profiles of the $\mathrm{Zn} / \mathrm{NVO}$ batteries based on electrolytes with and without $\mathrm{Na}_{2} \mathrm{SO}_{4}$ additive. They display two pairs of similar redox peaks, indicating that the addition of $\mathrm{Na}_{2} \mathrm{SO}_{4}$ leads to negligible change in the redox reactions of $\mathrm{Zn} / \mathrm{NVO}$ batteries. It is also affirmed by their charge/discharge curves (Supplementary Fig. 8). Moreover, the two pairs of redox peaks locating at $0.55 / 0.77$ and $0.85 / 1.06 \mathrm{~V}$ can be ascribed to the reversible redox reactions from $\mathrm{NaZn}_{0.1} \mathrm{~V}_{3} \mathrm{O}_{8} \cdot 1.5 \mathrm{H}_{2} \mathrm{O}$ to $\mathrm{H}_{2.14} \mathrm{NaZn}_{0.2} \mathrm{~V}_{3} \mathrm{O}_{8} \cdot 1.5 \mathrm{H}_{2} \mathrm{O}$ and then $\mathrm{H}_{3.9} \mathrm{NaZn}_{0.5} \mathrm{~V}_{3} \mathrm{O}_{8} \cdot 1.5 \mathrm{H}_{2} \mathrm{O}$ (corresponding calculation process and analysis see Supplementary Information and following energy storage mechanism section), corresponding to the valence changes of vanadium from $\mathrm{V}^{5+}$ to $\mathrm{V}^{4+}$ and $\mathrm{V}^{4+}$ to $\mathrm{V}^{3+}$, respectively ${ }^{50-52}$. More importantly, it is noted that, after first cycle, subsequent four cycles show a nearly overlapping shape in the $\mathrm{Zn} / \mathrm{NVO}$ battery with $\mathrm{ZnSO}_{4} / \mathrm{Na}_{2} \mathrm{SO}_{4}$ electrolyte (Supplementary Fig. 9). In contrast, the corresponding $\mathrm{CV}$ curves in the case of $\mathrm{ZnSO}_{4}$ electrolyte without $\mathrm{Na}_{2} \mathrm{SO}_{4}$ significantly decrease with the increase of cycles. These indicate that the addition of $\mathrm{Na}_{2} \mathrm{SO}_{4}$ endows $\mathrm{Zn} / \mathrm{NVO}$ battery with better reversibility of carrier insertion/extraction. Therefore, the capacity of $\mathrm{Zn} / \mathrm{NVO}$ battery with $\mathrm{Na}_{2} \mathrm{SO}_{4}$ additive can still stabilize at $221 \mathrm{mAh} \mathrm{g}^{-1}$ after 100 cycles with a retention rate of $90 \%$ at a current density of $1 \mathrm{~A} \mathrm{~g}^{-1}$, which is superior to that $\left(84 \mathrm{mAh} \mathrm{g}^{-1}\right.$, a retention rate of $34 \%$ ) of the case without $\mathrm{Na}_{2} \mathrm{SO}_{4}$ additive (Fig. 3b). Such excellent electrochemical performance is ascribed to the restriction of continuous NVO dissolution and $\mathrm{Zn}$ dendrite formation through the addition of $\mathrm{Na}_{2} \mathrm{SO}_{4}$, as suggested in Fig. 4a, b. There are lots of harsh black depositions that consist of $\mathrm{Na}, \mathrm{V}, \mathrm{Zn}, \mathrm{S}$, and $\mathrm{O}$ elements formed on the surface of $\mathrm{Zn}$ negative electrode from battery after 100 cycles at $1 \mathrm{~A} \mathrm{~g}^{-1}$ without $\mathrm{Na}_{2} \mathrm{SO}_{4}$ additive (Fig. 4a), suggesting that some side reactions have happened on the $\mathrm{Zn}$ negative electrode because of the dissolved NVO in the electrolyte. In contrast, the $\mathrm{Zn}$ negative electrode from battery with $\mathrm{Na}_{2} \mathrm{SO}_{4}$ additive is clean and smooth after 100 cycles at $1 \mathrm{~A}$ $\mathrm{g}^{-1}$ (Fig. 4b), revealing that $\mathrm{Na}_{2} \mathrm{SO}_{4}$ additive indeed avoids the side reactions and the growth of $\mathrm{Zn}$ dendrites on the $\mathrm{Zn}$ negative electrode. The morphology and structure evolution of NVO during the charge/discharge process is also important for the stable electrochemical properties of $\mathrm{Zn} / \mathrm{NVO}$ batteries. Compared with the original NVO nanobelts (Fig. 4c), the NVO nanobelts in the positive electrodes still display a similar morphology without obvious change after discharging to $0.3 \mathrm{~V}$ (Fig. $4 \mathrm{~d}$ ) and recharging to $1.25 \mathrm{~V}$ (Fig. 4e). Even after 100 cycles, the nanobelt 

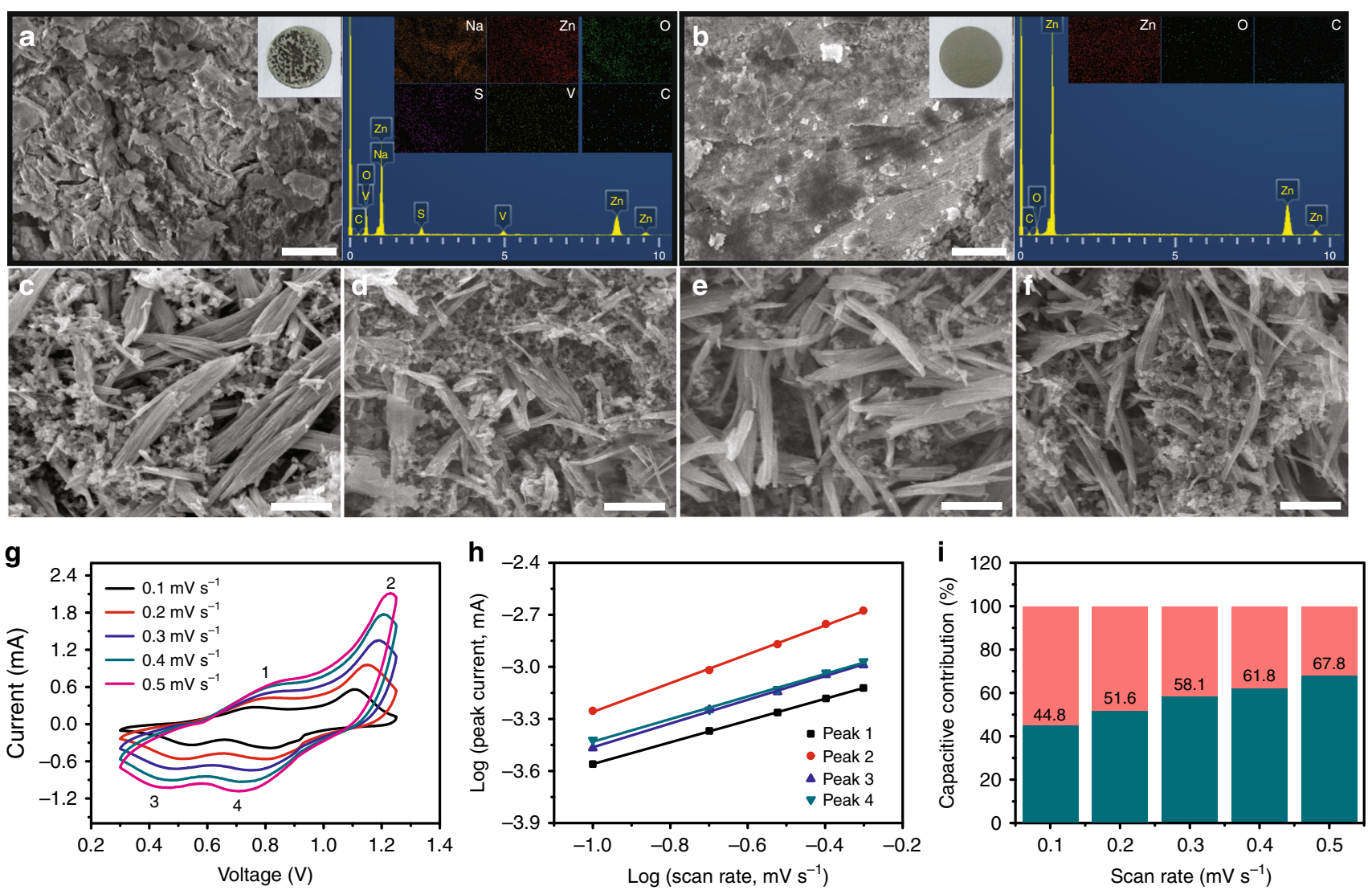

Fig. 4 Morphology change of $Z n$ negative electrode and NVO positive electrode after cycling and kinetics of electrochemical process. SEM images and corresponding EDS analysis of $\mathrm{Zn}$ negative electrodes $\left(1 \mathrm{Ag}^{-1}\right.$, 100th cycle) from $\mathrm{Zn} / \mathrm{NVO}$ batteries based on $\mathbf{a} \mathrm{ZnSO}_{4}$ and $\mathbf{b} \mathrm{ZnSO}_{4} / \mathrm{Na}_{2} \mathrm{SO}_{4}$ electrolytes. Scale bars, $2 \mu \mathrm{m}$. SEM images of NVO electrodes at different states: $\mathbf{c}$ origin, $\mathbf{d}$ first discharged to $0.3 \mathrm{~V}, \mathbf{e}$ first charged to $1.25 \mathrm{~V}$, and $\mathbf{f}$ after 100 cycles at $0.1 \mathrm{Ag}^{-1}$ in $\mathrm{ZnSO}_{4} / \mathrm{Na}_{2} \mathrm{SO}_{4}$ electrolyte. Scale bars, $1 \mu \mathrm{m}$. $\mathbf{g}$ CV curves of $\mathrm{NVO}$ electrode at different scan rates in $\mathrm{ZnSO}_{4} / \mathrm{Na}_{2} \mathrm{SO}_{4}$ electrolyte and $\mathbf{h}$ the corresponding plots of log (peak current) vs. log (scan rate) at each peak. $\mathbf{i}$ The capacitive contributions at different scan rates in $\mathrm{ZnSO}_{4} / \mathrm{Na}_{2} \mathrm{SO}_{4}$ electrolyte

morphology of NVO can still be distinguished clearly (Fig. 4f), suggesting high morphology and structure stability of NVO during the charge/discharge process. It is beneficial for the stable cycling performance of $\mathrm{Zn} / \mathrm{NVO}$ batteries. Therefore, the $\mathrm{Zn} /$ NVO batteries with $\mathrm{Na}_{2} \mathrm{SO}_{4}$ additive display long-term cycle life with a high capacity retention ratio of $82 \%$ even after 1000 cycles at $4 \mathrm{~A} \mathrm{~g}^{-1}$ (Fig. 3c).

Apart from the high capacity retention ratio, the NVO nanobelts also exhibit excellent rate capability, as displayed in Fig. 3d. They can display a high capacity of $165 \mathrm{mAh} \mathrm{g}^{-1}$ at a high current density of $4 \mathrm{Ag}^{-1}$ (the charge/discharge process was completed in $5 \mathrm{~min}$ ), maintaining $44 \%$ of that at $0.1 \mathrm{~A} \mathrm{~g}^{-1}$. This performance is much higher than that $\left(80 \mathrm{mAh} \mathrm{g}^{-1}\right.$ at $4 \mathrm{Ag}^{-1}$, maintaining $25 \%$ of that at $0.1 \mathrm{~A} \mathrm{~g}^{-1}$ ) of $\mathrm{NVO}$ nanorods (Supplementary Fig. 10) because the favorable nanobelt morphology is beneficial for the fast kinetics of the carrier insertion/ extraction. Furthermore, the plateaus in charge-discharge curves can still be easily distinguished even at the high current density of $4 \mathrm{~A} \mathrm{~g}^{-1}$. In addition, impressively, when the current density abruptly recovers from 4 to $0.1 \mathrm{~A} \mathrm{~g}^{-1}$ after 30 cycles, the capacity of NVO nanobelts is able to recover to $310 \mathrm{mAh} \mathrm{g}^{-1}$ (Supplementary Fig. 11). As a result, our Zn/NVO batteries display not only a superior energy density $\left(300 \mathrm{Wh} \mathrm{kg}^{-1}\right)$ but also an impressive power energy density $\left(3600 \mathrm{~W} \mathrm{~kg}^{-1}\right)$ based on the mass of $\mathrm{NVO}$ in positive electrode. Compared with previous reported ZIBs based on various active materials, the Zn/NVO batteries deliver steady and higher energy densities over a wide range of power densities, as displayed in the Ragone plots (Fig. 3e $)^{9,16,27,31,33}$. The high rate performance of $\mathrm{Zn} / \mathrm{NVO}$ batteries significantly depends on their kinetics origin, which was investigated by $\mathrm{CV}$ characterizations in detail. Figure $4 \mathrm{~g}$ displays the CV curves of the $\mathrm{Zn} / \mathrm{NVO}$ batteries at different scan rates from 0.1 to $0.5 \mathrm{mV} \mathrm{s}^{-1}$ with a voltage window from 0.3 to $1.25 \mathrm{~V}$. There are two reduction peaks and two oxidation peaks in each curve. Their peak currents $(i)$ and scan rates $(v)$ have a relationship as below: ${ }^{53,54}$

$$
i=a v^{\mathrm{b}},
$$

which can be rewritten as

$$
\log (i)=b \log (v)+\log (a),
$$

where $b$ represents the slope of $\log (i)$ vs. $\log (v)$ curve, which is often in a range of $0.5-1$. When $b$ value is 0.5 , the electrochemical process is controlled by ionic diffusion. If $b$ value reaches to 1 , the pseudocapacitance will dominate the charge/discharge process. By fitting the plots of $\log (i)$ vs. $\log (v)$ (Fig. 4 h), the calculated $b$ values of peak $1,2,3$, and 4 are $0.63,0.83,0.68$, and 0.65 , respectively, indicating that the electrochemical reaction of $\mathrm{Zn}$ / NVO batteries is controlled by ionic diffusion and pseudocapacitance synchronously. This characteristic is responsible for the high rate performance of the $\mathrm{Zn} / \mathrm{NVO}$ batteries. In addition, the capacitive contribution can be calculated through the following 

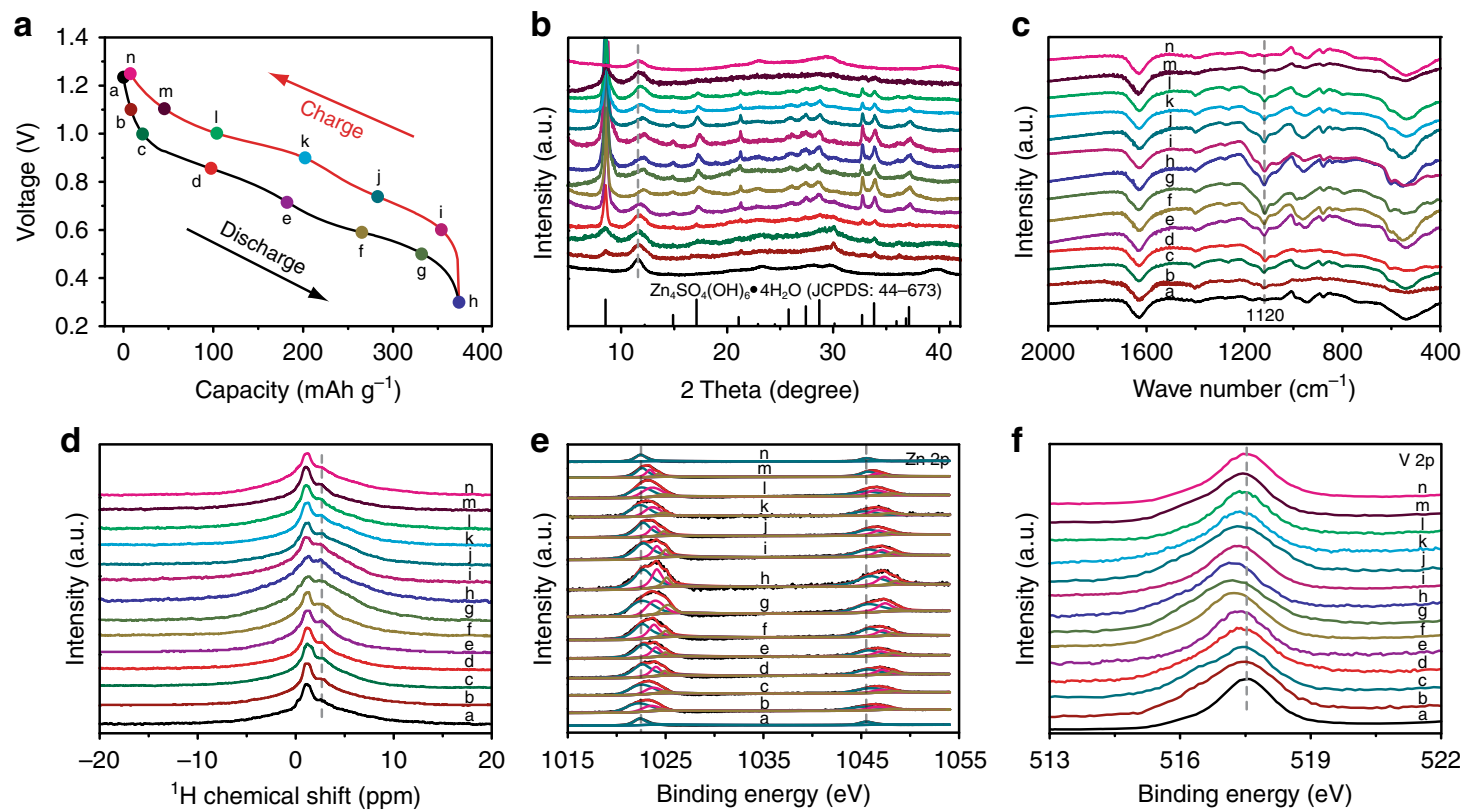

Fig. 5 Simultaneous $\mathrm{H}^{+}$and $\mathrm{Zn}^{2+}$ insertion/extraction mechanism. a Second charge/discharge curve of NVO nanobelts at $0.1 \mathrm{Ag}^{-1}$. Ex situ $\mathbf{b}$ XRD patterns, c FTIR spectra, $\mathbf{d}$ solid state ${ }^{1} \mathrm{H}$ NMR, and XPS spectra of $\mathbf{e}$ Zn $2 \mathrm{p}$ and $\mathbf{f} \vee 2 \mathrm{p}$ at selected states

equation $^{55,56}$ :

$$
i=k_{1} v+k_{2} v^{1 / 2}
$$

which can be reformulated as

$$
i / v^{1 / 2}=k_{1} v^{1 / 2}+k_{2},
$$

where $i, k_{1} v$, and $k_{2} v^{1 / 2}$ represent the current response, capacitive, and ionic diffusion contribution, respectively. Since $k_{1}$ can be obtained by fitting the $i / v^{1 / 2}$ vs. $v^{1 / 2}$ plots, the capacitive contribution is calculated to be $44.8 \%$ at the scan rate of 0.1 $\mathrm{mV} \mathrm{s}^{-1}$. With the increase of scan rate, the percentage of capacitive contribution raises to $51.6 \%, 58.1 \%, 61.8 \%$, and $67.8 \%$ at the scan rates of $0.2,0.3,0.4$, and $0.5 \mathrm{mV} \mathrm{s}^{-1}$, respectively (Fig. 4i), revealing that the $\mathrm{Zn} / \mathrm{NVO}$ batteries have favorable charge transfer kinetics.

The excellent performance of $\mathrm{Zn} / \mathrm{NVO}$ coin-type batteries motivated us to fabricate soft-packed batteries with a high theoretical capacity of $1520 \mathrm{mAh}$ (Supplementary Fig. 12a). They display a charge capacity of $1040 \mathrm{mAh}$ in the first cycle (completed in $0.5 \mathrm{~h}$ ), the corresponding energy density is 144 Wh kg-1 based on the total mass of NVO positive electrode and $\mathrm{Zn}$ negative electrode, which is higher than other aqueous lithium-ion batteries (50-100 $\mathrm{Wh} \mathrm{kg}^{-1}$ ) and aqueous sodium-ion batteries $\left(\sim 30 \mathrm{Wh} \mathrm{kg}^{-1}\right)^{8,57-59}$. Furthermore, according to the total weight of whole soft-packed battery, they still achieve a high energy density of $70 \mathrm{Wh} \mathrm{kg}^{-1}$ that is higher than those of commercial $\mathrm{Pb}$-acid and $\mathrm{Ni}$-Cd batteries ${ }^{23}$. In addition, it is noted that a high capacity of $800 \mathrm{mAh}$ can be obtained even after 100 cycles at $0.5 \mathrm{Ag}^{-1}$ (Supplementary Fig. 12b), displaying the potential in practical application.

Energy storage mechanism. At the selected states of second charge/discharge process, as marked in the Fig. 5a, various ex situ tests including XRD, FTIR, solid state ${ }^{1} \mathrm{H}$ nuclear magnetic resonance $\left({ }^{1} \mathrm{H} \mathrm{NMR}\right)$, and XPS were utilized to analyze the NVO positive electrodes for further understanding the energy storage mechanism of $\mathrm{Zn} / \mathrm{NVO}$ systems. It is interesting that
$\mathrm{Zn}_{4} \mathrm{SO}_{4}(\mathrm{OH})_{6} \cdot 4 \mathrm{H}_{2} \mathrm{O}$ (JCPDS: $\left.39-688\right)$ is successively formed during the discharge process, as reflected by the ex situ XRD analysis (Fig. 5b and Supplementary Fig. 13). Subsequently, $\mathrm{Zn}_{4} \mathrm{SO}_{4}(\mathrm{OH})_{6} \cdot 4 \mathrm{H}_{2} \mathrm{O}$ gradually disappears after charging from 0.3 to $1.25 \mathrm{~V}$. These results indicate the reversible and successive formation/decomposition of $\mathrm{Zn}_{4} \mathrm{SO}_{4}(\mathrm{OH})_{6} \cdot 4 \mathrm{H}_{2} \mathrm{O}$ on the positive electrode during the charge/discharge process, which was also proved by the FTIR spectra at the selected charge/discharge states (Fig. 5c). In the FTIR spectra, the intensity of peak at $1120 \mathrm{~cm}^{-1}$ belonging to $\mathrm{Zn}_{4} \mathrm{SO}_{4}(\mathrm{OH})_{6} \cdot 4 \mathrm{H}_{2} \mathrm{O}$ is gradually enhanced in the discharge process ${ }^{60}$. While in the charge process, it becomes weaker gradually and completely invisible at fully charged state. In the $\mathrm{Zn} / \mathrm{NVO}$ systems, the $\mathrm{OH}^{-}$in $\mathrm{Zn}_{4} \mathrm{SO}_{4}(\mathrm{OH})_{6} \cdot 4 \mathrm{H}_{2} \mathrm{O}$ comes from the decomposition of water in the aqueous $\mathrm{ZnSO}_{4} / \mathrm{Na}_{2} \mathrm{SO}_{4}$ electrolyte. As a result, a large amount of $\mathrm{H}^{+}$yields synchronously. To reach a neutral charge system, these $\mathrm{H}^{+}$could not exist in the electrolyte and would move into the positive electrode to balance its rich electron during the discharge procedure. To confirm the continuous insertion/extraction of $\mathrm{H}^{+}$in the NVO during the charge/discharge process, the NVO-based positive electrodes were characterized by ex situ solid state ${ }^{1} \mathrm{H}$ NMR at the selected states during the second cycling, as displayed in Fig. $5 \mathrm{~d}$. Compared with the initial state, there is an extra peak at $2.7 \mathrm{ppm}$ at the selected charge/discharge states. Since this peak is not assigned to the ${ }^{1} \mathrm{H}$ from the hydroxyl and crystal water of $\mathrm{Zn}_{4} \mathrm{SO}_{4}(\mathrm{OH})_{6} \cdot 4 \mathrm{H}_{2} \mathrm{O}$, which is usually located at $1.5 \mathrm{ppm}^{24}$, this extra peak would be ascribed to the $\mathrm{H}^{+}$that inserted in the NVO during the discharge process. This peak is gradually enhanced during discharge process. Reversibly, it is then reduced and finally returns to the initial state during the charge process. It indicates the continuous and reversible insertion/extraction of $\mathrm{H}^{+}$in the NVO during the charge/discharge process.

In addition to the reversible and successive insertion/extraction of $\mathrm{H}^{+}$, whether $\mathrm{Zn}^{2+}$ takes part in the energy storage in $\mathrm{Zn} / \mathrm{NVO}$ systems was investigated by the XPS spectra at the selected charge/discharge states (Fig. 5e and Supplementary Fig. 14). In the $\mathrm{Zn} 2 \mathrm{p}$ spectra of NVO electrodes (Fig. 5e), three pairs of $\mathrm{Zn}^{2+}$ peaks located at 1023/1046, 1024/1047, and 1025/1048 eV are assigned to the inserted $\mathrm{Zn}^{2+}$ in NVO, as well as the $\mathrm{Zn}^{2+}$ in $\mathrm{Zn}$ 
$(\mathrm{OH})_{2}$ and $\mathrm{ZnSO}_{4}$ from $\mathrm{Zn}_{4} \mathrm{SO}_{4}(\mathrm{OH})_{6} \cdot 4 \mathrm{H}_{2} \mathrm{O}$, respectively. It is noted that a small quantity of the inserted $\mathrm{Zn}^{2+}$ in NVO is detected at the initial state of second cycling (state a in Fig. 5a). It reveals that some of the inserted $\mathrm{Zn}^{2+}$ were not extracted from $\mathrm{NVO}$ even after full charging at first cycling, which is further confirmed by the XPS spectra at the selected charge/discharge states of first cycling (Supplementary Fig. 14). However, in the second cycling, there is a gradual increase in the intensity of peaks belonging to the inserted $\mathrm{Zn}^{2+}$ in NVO during the discharge process (Fig. 5e). Subsequently, this peak is consecutively decreased and finally reaches the initial state during charge process. It suggests the continuous and reversible insertion/ extraction of $\mathrm{Zn}^{2+}$ in the NVO during cycling. Furthermore, the peaks of the $\mathrm{Zn}^{2+}$ in $\mathrm{Zn}(\mathrm{OH})_{2}$ and $\mathrm{ZnSO}_{4}$ from $\mathrm{Zn}_{4} \mathrm{SO}_{4}(\mathrm{OH})_{6} \cdot 4 \mathrm{H}_{2} \mathrm{O}$ also display a similar trend, suggesting the reversible conversion of $\mathrm{Zn}_{4} \mathrm{SO}_{4}(\mathrm{OH})_{6} \cdot 4 \mathrm{H}_{2} \mathrm{O}$ during cycling. Therefore, according to above discussion, it is confirmed that $\mathrm{H}$ + and $\mathrm{Zn}^{2+}$ can simultaneously insert into and extract from NVO during cycling, which is quite different from the consequent insertion/extraction mechanism of $\mathrm{H}^{+}$and $\mathrm{Zn}^{2+}$ into/from $\mathrm{MnO}_{2}{ }^{34}$.

Owing to the polarity, the insertion of $\mathrm{H}^{+}$and $\mathrm{Zn}^{2+}$ would result in the decrease of $\mathrm{d}$-space in $\mathrm{NVO}$, as reflected by XRD patterns, where the peak at $12.2^{\circ}$ (the (001) reflection of NVO) gradually shifts to high degree during discharge process. However, impressively, the peak at $12.2^{\circ}$ finally recovers to the initial state during the charge process (Fig. 5b), indicating the reversible structural evolution of NVO due to the simultaneous insertion/extraction of $\mathrm{H}^{+}$and $\mathrm{Zn}^{2+}$. Furthermore, even after 100 cycles the NVO still remain good structural reversibility of NVO during the cycling, as suggested by their XRD patterns (Supplementary Fig. 15). In addition, to understand the repeatability of energy storage mechanism, the NVO electrode was also characterized by the ex situ XRD at the selected states of 10th charge/discharge process (Supplementary Fig. 16). They display similar XRD patterns at the selected states compared with the case of second cycle, suggesting that the mechanism that was suggested by second cycle is implemented for the following cycles.

The insertion/extraction of $\mathrm{H}^{+}$and $\mathrm{Zn}^{2+}$ will lead to the valence change of vanadium in NVO. The V 2p peak of the XPS spectra at the selected charge/discharge states shifts to low bonding energy (low valence) during the discharge process, corresponding to the reduction of vanadium (Fig. 5f). And then it is backed to the original bonding energy gradually in the charge process since the vanadium is oxidized to initial state. In addition, it is noted that the peak shift of $\mathrm{V} 2 \mathrm{p}$ at the discharge process from state a to state $\mathrm{d}$ and charge process from state $\mathrm{i}$ to state $\mathrm{n}$ is small, indicating that $\mathrm{H}^{+}$and $\mathrm{Zn}^{2+}$ insertion/extraction is slower at the discharge stage from $1.25-0.85 \mathrm{~V}$ and charge stage from $1.0-1.25 \mathrm{~V}$.

Since the dissolution of discharge products in electrolyte can be ignored (Supplementary Information for details) and no electrolyte or other deposits remained in the electrodes after being washed by deionized water, as suggested by above XRD and FTIR results, the quantify of the inserted $\mathrm{Zn}^{2+}$ in NVO can be directly reflected by inductively coupled plasma atomic emission spectroscopy (ICP-AES) of the charge/discharge products on the positive electrode (Supplementary Information for details). The mole ratios of $\mathrm{Na}, \mathrm{Zn}$, and $\mathrm{V}$ in the charge/discharge products are 1:3.1:3 (first discharge at 0.3 V) and 1:0.1:3 (first charge at 1.25 V), respectively. According to the first discharge and charge capacities, the electron transfer numbers are 4.9 and 4.7, respectively. Therefore, the inserted $\mathrm{H}^{+}$and $\mathrm{Zn}^{2+}$ can be quantified via combining the ICP-AES results with the electron transfer numbers to understand the discharge and charge products. The first discharge products are
$\mathrm{H}_{3.9} \mathrm{NaZn}_{0.5} \mathrm{~V}_{3} \mathrm{O}_{8} \cdot 1.5 \mathrm{H}_{2} \mathrm{O}$ and $\mathrm{Zn}_{4} \mathrm{SO}_{4}(\mathrm{OH})_{6} \cdot 4 \mathrm{H}_{2} \mathrm{O}$, and the first charge product is $\mathrm{NaZn}_{0.1} \mathrm{~V}_{3} \mathrm{O}_{8} \cdot 1.5 \mathrm{H}_{2} \mathrm{O}$. Hence, the electrochemical reactions of the aqueous $\mathrm{Zn} / \mathrm{NVO}$ batteries can be summarized as below:

First discharge:

Positive electrode:

$$
3.9 \mathrm{H}_{2} \mathrm{O} \leftrightarrow 3.9 \mathrm{H}^{+}+3.9 \mathrm{OH}^{-}
$$

$1.95 \mathrm{Zn}^{2+}+0.65 \mathrm{ZnSO}_{4}+3.9 \mathrm{OH}^{-}+2.6 \mathrm{H}_{2} \mathrm{O} \leftrightarrow 0.65 \mathrm{Zn}_{4} \mathrm{SO}_{4}(\mathrm{OH})_{6} \cdot 4 \mathrm{H}_{2} \mathrm{O}$

$$
\begin{array}{r}
\mathrm{NaV}_{3} \mathrm{O}_{8} \cdot 1.5 \mathrm{H}_{2} \mathrm{O}+3.9 \mathrm{H}^{+}+0.5 \mathrm{Zn}^{2+}+4.9 \mathrm{e}^{-} \\
\rightarrow \mathrm{H}_{3.9} \mathrm{NaZn}_{0.5} \mathrm{~V}_{3} \mathrm{O}_{8} \cdot 1.5 \mathrm{H}_{2} \mathrm{O}
\end{array}
$$

Negative electrode:

$$
2.45 \mathrm{Zn} \leftrightarrow 2.45 \mathrm{Zn}^{2+}+4.9 \mathrm{e}^{-}
$$

Overall:

$$
\begin{aligned}
& \mathrm{NaV}_{3} \mathrm{O}_{8} \cdot 1.5 \mathrm{H}_{2} \mathrm{O}+0.65 \mathrm{ZnSO}_{4}+6.5 \mathrm{H}_{2} \mathrm{O}+2.45 \mathrm{Zn} \rightarrow \\
& 0.65 \mathrm{Zn}_{4} \mathrm{SO}_{4}(\mathrm{OH})_{6} \cdot 4 \mathrm{H}_{2} \mathrm{O}+\mathrm{H}_{3.9} \mathrm{NaZn}_{0.5} \mathrm{~V}_{3} \mathrm{O}_{8} \cdot 1.5 \mathrm{H}_{2} \mathrm{O}
\end{aligned}
$$

Subsequent cycles:

Positive electrode:

$$
\begin{aligned}
\mathrm{H}_{3.9} \mathrm{NaZn}_{0.5} \mathrm{~V}_{3} \mathrm{O}_{8} \cdot 1.5 \mathrm{H}_{2} \mathrm{O} \leftrightarrow \mathrm{NaZn}_{0.1} \mathrm{~V}_{3} \mathrm{O}_{8} \cdot 1.5 \mathrm{H}_{2} \mathrm{O} \\
+3.9 \mathrm{H}^{+}+0.4 \mathrm{Zn}^{2+}+4.7 \mathrm{e}^{-}
\end{aligned}
$$

$0.65 \mathrm{Zn}_{4} \mathrm{SO}_{4}(\mathrm{OH})_{6} \cdot 4 \mathrm{H}_{2} \mathrm{O} \leftrightarrow 1.95 \mathrm{Zn}^{2+}+0.65 \mathrm{ZnSO}_{4}+3.9 \mathrm{OH}^{-}+2.6 \mathrm{H}_{2} \mathrm{O}$

$$
3.9 \mathrm{H}^{+}+3.9 \mathrm{OH}^{-} \leftrightarrow 3.9 \mathrm{H}_{2} \mathrm{O}
$$

Negative electrode:

$$
2.35 \mathrm{Zn}^{2+}+4.7 \mathrm{e}^{-} \leftrightarrow 2.35 \mathrm{Zn}
$$

Overall:

$$
\begin{gathered}
0.65 \mathrm{Zn}_{4} \mathrm{SO}_{4}(\mathrm{OH})_{6} \cdot 4 \mathrm{H}_{2} \mathrm{O}+\mathrm{H}_{3.9} \mathrm{NaZn}_{0.5} \mathrm{~V}_{3} \mathrm{O}_{8} \cdot 1.5 \mathrm{H}_{2} \mathrm{O} \leftrightarrow \\
\mathrm{NaZn}_{0.1} \mathrm{~V}_{3} \mathrm{O}_{8} \cdot 1.5 \mathrm{H}_{2} \mathrm{O}+0.65 \mathrm{ZnSO}_{4}+6.5 \mathrm{H}_{2} \mathrm{O}+2.35 \mathrm{Zn}
\end{gathered}
$$

In the first discharge process, the $\mathrm{H}^{+}$and $\mathrm{Zn}^{2+}$ simultaneously insert into NVO to form $\mathrm{H}_{3.9} \mathrm{NaZn}_{0.5} \mathrm{~V}_{3} \mathrm{O}_{8} \cdot 1.5 \mathrm{H}_{2} \mathrm{O}$, which is not a completely reversible reaction. After being charged to $1.25 \mathrm{~V}$, the $\mathrm{H}^{+}$and partial $\mathrm{Zn}^{2+}$ are simultaneously extracted to obtain $\mathrm{NaZn}_{0.1} \mathrm{~V}_{3} \mathrm{O}_{8} \cdot 1.5 \mathrm{H}_{2} \mathrm{O}$. This procedure is reversible and the following cycles implement this mechanism. According to the overall reaction equation, the capacity contributions of $\mathrm{H}^{+}$and $\mathrm{Zn}^{2+}$ were calculated to be $83 \%$ (about $315 \mathrm{mAh} \mathrm{g}^{-1}$ ) and $17 \%$ (about $65 \mathrm{mAh} \mathrm{g}^{-1}$ ), respectively. Such behavior is different from the previously reported cases, where only $\mathrm{Zn}^{2+}$ or $\mathrm{H}^{+}$inserts into host materials or $\mathrm{H}^{+}$first inserts into host materials and then $\mathrm{Zn}^{2}$ ${ }^{+}$with two steps ${ }^{16,24,34}$. As discussed above, the $\mathrm{ZnSO}_{4}$ and $\mathrm{H}_{2} \mathrm{O}$ in electrolyte participate in the electrochemical reactions during cycling. When the $\mathrm{ZnSO}_{4}$ and $\mathrm{H}_{2} \mathrm{O}$ are also considered, the 

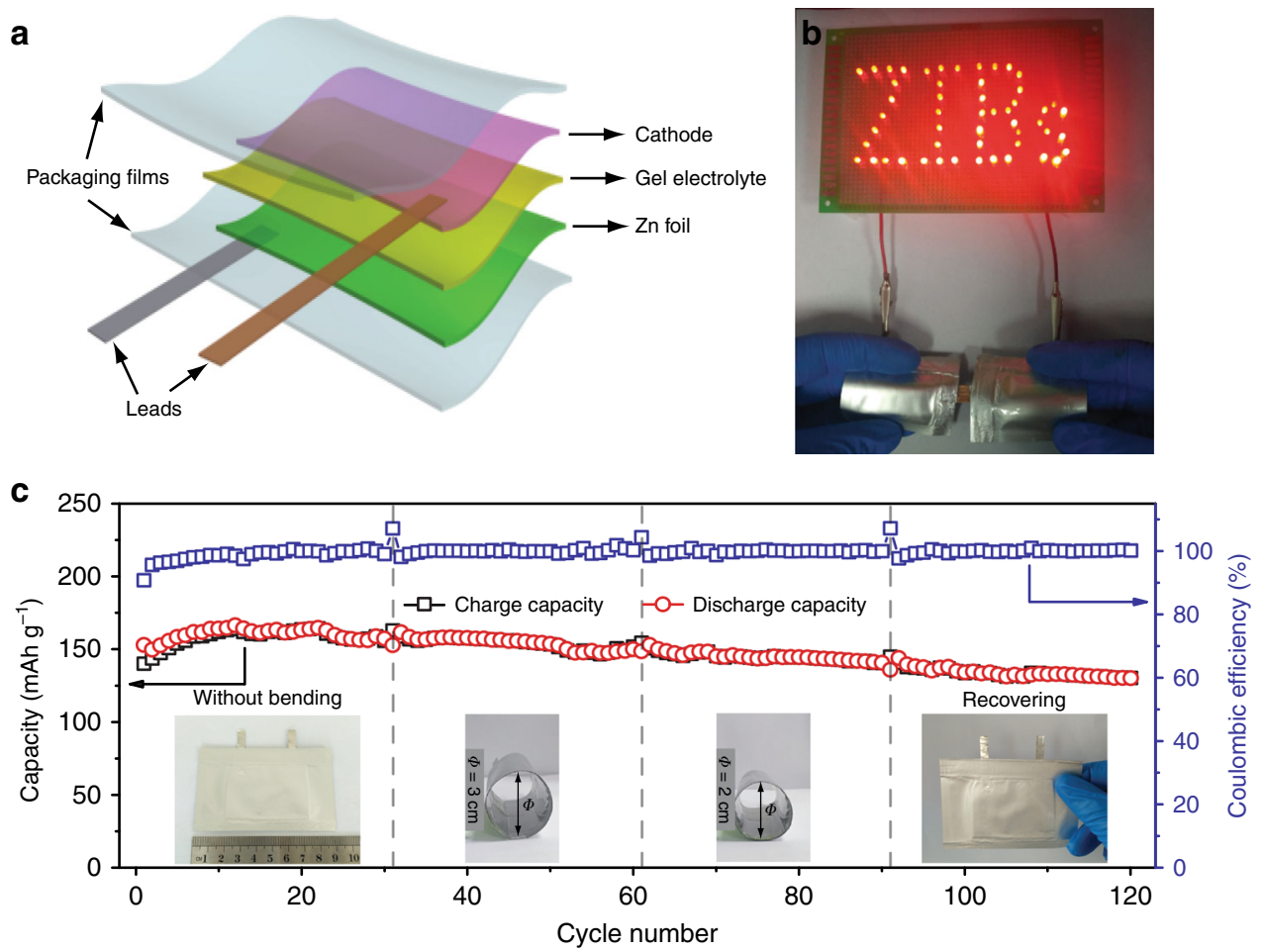

Fig. 6 Configuration and performance of flexible quasi-solid-state Zn/NVO batteries. a Schematic diagram of a flexible quasi-solid-state Zn/NVO battery. b LED array containing 52 bulbs powered by two flexible quasi-solid-state Zn/NVO batteries under bending state. c Cycling performance under different bending states $\left(0.5 \mathrm{~A} \mathrm{~g}^{-1}\right)$ of the flexible quasi-solid-state $\mathrm{Zn} / \mathrm{NVO}$ battery. The insets show the optical images of the quasi-solid-state $\mathrm{Zn} / \mathrm{NVO}$ battery at corresponding bending states

corresponding energy density and power density of $\mathrm{Zn} / \mathrm{NVO}$ batteries are about $180 \mathrm{Wh} \mathrm{kg}^{-1}$ and $2160 \mathrm{~W} \mathrm{~kg}^{-1}$, respectively.

Flexible quasi-solid-state Zn/NVO batteries. Recent development of flexible electronic devices has raised the urgent requirements for energy storage devices with high flexibility ${ }^{61-65}$. Since the flexible energy storage devices often suffer from the possible leakage of harmful electrolytes during the bending process, aqueous ZIBs will be safer in comparison with other batteries based on organic electrolytes ${ }^{61,66}$. Compared with liquid electrolytes, quasi-solid-state electrolytes are more beneficial for preventing the leakage of electrolytes. Moreover, quasi-solid-state electrolytes exhibit high flexibility, and can simultaneously control the dissolution of active materials and the deposition of dendrites ${ }^{67,68}$. Therefore, quasi-solid-state ZIBs will be good candidates for flexible energy storage devices. Besides, the morphology of nanobelts guarantees our NVO positive electrodes to be flexible without obvious cracks even at bending state (Supplementary Fig. 17). As a proof of concept, flexible $\mathrm{Zn} / \mathrm{NVO}$ batteries were assembled by sandwiching quasi-solid-state gelation $/ \mathrm{ZnSO}_{4}$ electrolyte between the NVO positive electrode and $\mathrm{Zn}$ foil, and then sealed by Al-plastic films (Fig. 6a and Supplementary Fig. 18). Although the performance of the quasi-solid-state $\mathrm{Zn} /$ $\mathrm{NVO}$ batteries cannot touch that of batteries based on aqueous $\mathrm{ZnSO}_{4} / \mathrm{Na}_{2} \mathrm{SO}_{4}$ electrolyte due to the degraded ionic conductivity of quasi-solid-state electrolyte, they still display the excellent capacities of $288,228,160,115$, and $80 \mathrm{mAh} \mathrm{g}^{-1}$ at $0.1,0.2,0.5,1$, and $2 \mathrm{~A} \mathrm{~g}^{-1}$, respectively based on the mass of NVO in positive electrode (Supplementary Fig. 19a), which are better than most of the reported aqueous $\mathrm{ZIBs}^{15,18,20-22,25-27,29,31}$. Furthermore, when the current density abruptly recovers from 2 to $0.1 \mathrm{Ag} \mathrm{g}^{-1}$ after 25 cycles, the capacity can recover to $270 \mathrm{mAhg}^{-1}$, indicating the excellent rate performance of our quasi-solid-state $\mathrm{Zn} / \mathrm{NVO}$ batteries. In addition, the corresponding charge/discharge curves at different current densities deliver two reduction and two oxidation plateaus, respectively (Supplementary Fig. 19b), which are similar to those in aqueous $\mathrm{ZnSO}_{4} / \mathrm{Na}_{2} \mathrm{SO}_{4}$ electrolyte, indicating that the quasi-solid-state electrolyte nearly has no influence on the reaction mechanism of $\mathrm{Zn} / \mathrm{NVO}$ systems.

To further understand the energy storage mechanisms of the quasi-solid-state Zn/NVO battery, the NVO-based electrodes from quasi-solid-state $\mathrm{Zn} / \mathrm{NVO}$ battery was characterized by ex situ XRD at the selected states of second charge/discharge process (Supplementary Fig. 20). The XRD patterns of the NVObased electrodes from quasi-solid-state $\mathrm{Zn} / \mathrm{NVO}$ battery are similar with the case of NVO-based electrodes from liquid $\mathrm{Zn}$ / NVO battery, indicating that quasi-solid-state Zn/NVO battery shows a similar energy storage mechanism. In addition, in the quasi-solid-state electrolyte, the content of water is about $71 \%$, which is enough to offer water for participating in the reactions, like the case of $\mathrm{Zn} / \mathrm{NVO}$ battery based on liquid electrolyte. It is noted that the intensity of peaks corresponding to $\mathrm{Zn}_{4} \mathrm{SO}_{4}(\mathrm{OH})_{6} \cdot 4 \mathrm{H}_{2} \mathrm{O}$ is gradually enhanced during discharge process. Subsequently, it is reduced and finally returns to the initial state. It indicates the reversible formation/decomposition of $\mathrm{Zn}_{4} \mathrm{SO}_{4}(\mathrm{OH})_{6} \cdot 4 \mathrm{H}_{2} \mathrm{O}$ on $\mathrm{NVO}$ during the charge/discharge process in quasi-solid-state $\mathrm{Zn} / \mathrm{NVO}$ battery. It is similar to the case of Zn/NVO battery based on liquid electrolyte.

In order to demonstrate the viability of our quasi-solid-state $\mathrm{Zn} / \mathrm{NVO}$ batteries as flexible energy storage devices, we tested the cycling performance of a representative battery with a length of 9 $\mathrm{cm}$ at different bending states. As shown in Fig. $6 \mathrm{c}$, it delivers a stable capacity of $160 \mathrm{mAh} \mathrm{g}^{-1}$ at a current density of $0.5 \mathrm{~A} \mathrm{~g}^{-1}$ after activation in the initial 10 cycles. After 30 cycles, when the battery was bent to form a circular column with a diameter of 3 
$\mathrm{cm}$ and even $2 \mathrm{~cm}$, it was still able to display a steady capacity of 157 and $145 \mathrm{mAh} \mathrm{g}^{-1}$, respectively. Moreover, after the battery recovered from bending state to flat state after 90 cycles, the capacity could be still up to $133 \mathrm{mAh} \mathrm{g}^{-1}$. During such a bending process, the battery is always able to charge/discharge well with only a slight capacity fading, displaying the high stability of the quasi-solid-state $\mathrm{Zn} / \mathrm{NVO}$ batteries as flexible energy storage devices. To demonstrate the flexibility of the resultant quasisolid-state $\mathrm{Zn} / \mathrm{NVO}$ batteries via a simple visual cue, we integrated two quasi-solid-state $\mathrm{Zn} / \mathrm{NVO}$ batteries in series. They can light up fifty-two light-emitting diodes with a shape of "ZIBs" even under bending state (Fig. 6b), illustrating the practical application potential of our flexible quasi-solid-state $\mathrm{Zn} / \mathrm{NVO}$ batteries.

\section{Discussion}

The performance of rechargeable aqueous ZIBs inevitably depends on the host electrodes and optimal electrolytes to a large extent $^{16,24,69}$. Owing to the nanobelt morphology and appropriate interlayer spacing, NVO nanobelts were used as the positive electrodes of high performance aqueous $\mathrm{ZIBs,} \mathrm{in} \mathrm{which} \mathrm{ZnSO}_{4}$ aqueous solution with $\mathrm{Na}_{2} \mathrm{SO}_{4}$ additive was used as electrolyte. The $\mathrm{Na}_{2} \mathrm{SO}_{4}$ additive not only limits the continuous dissolution of $\mathrm{NVO}$ via changing the dissolution equilibrium of $\mathrm{Na}^{+}$from $\mathrm{NVO}$ electrodes, but also synchronously restricts the growth of $\mathrm{Zn}$ dendrites based on an electrostatic shield mechanism ${ }^{49}$, since $\mathrm{Na}$ + possesses a lower reduction potential than $\mathrm{Zn}^{2+}$. More importantly, a simultaneous $\mathrm{H}^{+}$and $\mathrm{Zn}^{2+}$ insertion/extraction process is achieved in our highly reversible $\mathrm{Zn} / \mathrm{NVO}$ system, which is different from conventional ZIBs with only $\mathrm{Zn}^{2+}$ insertion/extraction and some $\mathrm{Zn} / \mathrm{MnO}_{2}$ systems with $\mathrm{H}^{+}$or two-step $\mathrm{H}^{+} / \mathrm{Zn}^{2+}$ insertion/extraction process ${ }^{24,33,34}$. Such novel energy release/storage mechanism remarkably enhances the performance of $\mathrm{Zn} / \mathrm{NVO}$ batteries, which deliver a superior reversible capacity of $380 \mathrm{mAh} \mathrm{g}^{-1}$ (corresponding energy density: $300 \mathrm{Wh} \mathrm{kg}^{-1}$ ), a high capacity retention of $82 \%$ after 1000 cycles at $4 \mathrm{Ag}^{-1}$. The simultaneous $\mathrm{H}^{+}$and $\mathrm{Zn}^{2+}$ insertion/ extraction mechanism will guide further developing new appropriate host materials for aqueous metal-ion batteries with high performance. Moreover, the nanobelt morphology of NVO makes the corresponding positive electrodes possess the capacity of enduring the high strain without obvious cracks at bending state, guaranteeing that the NVO nanobelts can act as the positive electrodes of flexile ZIBs. As a proof of concept, flexible softpackaged $\mathrm{Zn} / \mathrm{NVO}$ batteries were assembled using quasi-solidstate gelation $/ \mathrm{ZnSO}_{4}$ as electrolyte. Flexible $\mathrm{Zn} / \mathrm{NVO}$ batteries still show a high capacity of $288 \mathrm{mAh} \mathrm{g}^{-1}$ and superior rate capability even quasi-solid-state electrolyte is used. Impressively, they are able to remain stable electrochemical properties under different bending states. Their high flexibility and excellent electrochemical performance of flexible quasi-solid-state $\mathrm{Zn}$ / NVO batteries will pave the way for the potential application of ZIBs as portable, flexible, and wearable energy storage devices.

\footnotetext{
Methods

Materials. Super P, polyvinylidene fluoride (PVDF) and filter papers were purchased from Sinopharm Chemical Reagent Co., Ltd. Vanadium pentoxide, sodium chloride, sodium sulfate, zinc sulfate, and 1-methyl-2-pyrrolidone (NMP) were purchased from Alfa Aesar. Zn foils and gelatin were from Sigma-Aldrich and Beijing Solarbio Science \& Technology Co., Ltd., respectively. Al-plastic films were from Aladdin.
}

Preparation of NVO nanobelts. One gram of commercial $\mathrm{V}_{2} \mathrm{O}_{5}$ powder was added into $15 \mathrm{~mL}$ of $\mathrm{NaCl}$ aqueous solution $(2 \mathrm{M})$. After stirring for $96 \mathrm{~h}$ at $30^{\circ} \mathrm{C}$, the suspension was washed with deionized water for several times. Finally, the black red product was obtained by freeze-drying.
Fabrication of quasi-solid-state electrolyte. A measure of 1.5 grams of gelatin was added into $6 \mathrm{~mL}$ of $\mathrm{ZnSO}_{4}$ aqueous solution $(1 \mathrm{M})$ under magnetic stirring at $60{ }^{\circ} \mathrm{C}$. After $0.5 \mathrm{~h}$, the solution became transparent and was then poured into a watch glass with a diameter of $9.5 \mathrm{~cm}$ to gel at room temperature. After that, the gel electrolyte film was peeled from the watch glass and cut into desired size.

Assembly of Zn/NVO batteries. The positive electrode was prepared by mixing NVO nanobelts, super $\mathrm{P}$ and PVDF in a weight ratio of 7:2:1 by NMP, then casting the slurry on steel meshes. After drying at $80^{\circ} \mathrm{C}$, the positive electrode with $2 \mathrm{mg}$ $\mathrm{cm}^{-2}$ NVO nanobelts was achieved. CR2032 coin cells were assembled by a traditional method using filter papers and $\mathrm{Zn}$ foils as separators and negative electrodes, respectively. The aqueous electrolyte for coin cells was $1 \mathrm{M} \mathrm{ZnSO}_{4}$ or $1 \mathrm{M}$ $\mathrm{ZnSO}_{4} / 1 \mathrm{M} \mathrm{Na}_{2} \mathrm{SO}_{4}$. The aqueous electrolyte for liquid soft-packaged batteries was $1 \mathrm{M} \mathrm{ZnSO}_{4} / 1 \mathrm{M} \mathrm{Na}_{2} \mathrm{SO}_{4}$. Liquid soft-packaged batteries were assembled by sandwiching separator and electrolyte between the NVO positive electrode and $\mathrm{Zn}$ foil, and then sealed by Al-plastic films. Quasi-solid-state batteries were fabricated by sandwiching gelatin/ZnSO ${ }_{4}$ gel electrolyte between NVO positive electrode and $\mathrm{Zn}$ foil without additional separators, and then packaged by Al-plastic films.

Characterization. The morphology of NVO was characterized by SEM (JEOL JSM-7500F) and TEM (JEOL-2100 F, $200 \mathrm{kV}$ ) with energy dispersive spectroscopy (EDS) for elemental analysis. XRD tests were performed on Rigaku Ultima IV with $\mathrm{Cu} \mathrm{Ka}$ radiation. FTIR and XPS spectra were collected through Bruker Tensor II and PerkinElmer PHI 1600 ESCA, respectively. The solid state ${ }^{1} \mathrm{H}$ NMR spectra were taken from a $300 \mathrm{MHz}$ superconducting NMR spectrometer (Varian Infinitplus-300). ICP-AES results were obtained from PerkinElmer Optima 8300. CV curves were measured by an electrochemical workstation $(\mathrm{CHI} 660 \mathrm{E})$ with a voltage window of $0.3-1.25 \mathrm{~V}$ at different scan rates from 0.1 to $0.5 \mathrm{mV} \mathrm{s}^{-1}$. Galvanostatic charge/discharge tests were performed on a battery test system (LAND CT2001A) with a voltage range from 0.3 to $1.25 \mathrm{~V}$.

Data availability. The authors declare that all the relevant data are available within the paper and its Supplementary Information file or from the corresponding author upon reasonable request.

Received: 31 October 2017 Accepted: 30 March 2018

Published online: 25 April 2018

\section{References}

1. Armand, M. \& Tarascon, J. M. Building better batteries. Nature 451, 652-657 (2008).

2. Dunn, B., Kamath, H. \& Tarascon, J. M. Electrical energy storage for the grid: a battery of choices. Science 334, 928-935 (2011).

3. Yabuuchi, N., Kubota, K., Dahbi, M. \& Komaba, S. Research development on sodium-ion batteries. Chem. Rev. 114, 11636-11682 (2014).

4. $\mathrm{Hu}, \mathrm{X}$. et al. Rechargeable room-temperature $\mathrm{Na}-\mathrm{CO}_{2}$ batteries. Angew. Chem. Int. Ed. 55, 6482-6486 (2016).

5. Zhao, Q., Yan, Z., Chen, C. \& Chen, J. Spinels: controlled preparation, oxygen reduction/evolution reaction application, and beyond. Chem. Rev. 117, 10121-10211 (2017).

6. Yamada, Y. et al. Hydrate-melt electrolytes for high-energy-density aqueous batteries. Nat. Energy 1, 16129 (2016).

7. Zhang, N. et al. Cation-deficient spinel $\mathrm{ZnMn}_{2} \mathrm{O}_{4}$ cathode in $\mathrm{Zn}\left(\mathrm{CF}_{3} \mathrm{SO}_{3}\right)_{2}$ electrolyte for rechargeable aqueous $\mathrm{Zn}$-ion battery. J. Am. Chem. Soc. 138, 12894-12901 (2016)

8. Kim, H. et al. Aqueous rechargeable $\mathrm{Li}$ and $\mathrm{Na}$ ion batteries. Chem. Rev. 114, 11788-11827 (2014)

9. Lee, J., Ju, J. B., Cho, W. I., Cho, B. W. \& Oh, S. H. Todorokite-type $\mathrm{MnO}_{2}$ as a zinc-ion intercalating material. Electrochim. Acta 112, 138-143 (2013).

10. Lee, B. et al. Elucidating the intercalation mechanism of zinc ions into $\alpha-$ $\mathrm{MnO}_{2}$ for rechargeable zinc batteries. Chem. Commun. 51, 9265-9268 (2015).

11. Haupler, B. et al. Aqueous zinc-organic polymer battery with a high rate performance and long lifetime. NPG Asia Mater. 8, e283 (2016).

12. $\mathrm{Xu}, \mathrm{D}$. et al. Preparation and characterization of $\mathrm{MnO}_{2}$ /acid-treated CNT nanocomposites for energy storage with zinc ions. Electrochim. Acta 133, 254-261 (2014).

13. $\mathrm{Li}, \mathrm{H}$. et al. Enhancement on cycle performance of $\mathrm{Zn}$ anodes by activated carbon modification for neutral rechargeable zinc ion batteries. J. Electrochem. Soc. 162, A1439-A1444 (2015).

14. Lee, B. et al. Critical role of $\mathrm{pH}$ evolution of electrolyte in the reaction mechanism for rechargeable zinc batteries. ChemSusChem 9, 2948-2956 (2016).

15. Kaveevivitchai, W. \& Manthiram, A. High-capacity zinc-ion storage in an open-tunnel oxide for aqueous and nonaqueous $\mathrm{Zn}$-ion batteries. J. Mater. Chem. A 4, 18737-18741 (2016). 
16. Kundu, D., Adams, B. D., Duffort, V., Vajargah, S. H. \& Nazar, L. F. A highcapacity and long-life aqueous rechargeable zinc battery using a metal oxide intercalation cathode. Nat. Energy 1, 16119 (2016).

17. Alfaruqi, M. H. et al. Electrochemical zinc intercalation in lithium vanadium oxide: a high-capacity zinc-ion battery cathode. Chem. Mater. 29, 1684-1694 (2017).

18. He, P. et al. Layered $\mathrm{VS}_{2}$ nanosheet-based aqueous $\mathrm{Zn}$ ion battery cathode. Adv. Energy Mater. 7, 1601920 (2017).

19. Jiang, B. et al. Manganese sesquioxide as cathode material for multivalent zinc ion battery with high capacity and long cycle Life. Electrochim. Acta 229, 422-428 (2017).

20. Alfaruqi, M. H. et al. Enhanced reversible divalent zinc storage in a structurally stable $\mathrm{a}-\mathrm{MnO}_{2}$ nanorod electrode. J. Power Sources 288, 320-327 (2015).

21. Alfaruqi, M. H. et al. A layered $\delta-\mathrm{MnO}_{2}$ nanoflake cathode with high zincstorage capacities for eco-friendly battery applications. Electrochem. Commun. 60, 121-125 (2015).

22. Alfaruqi, M. H. et al. Electrochemically induced structural transformation in a $\gamma-\mathrm{MnO}_{2}$ cathode of a high capacity zinc-ion battery system. Chem. Mater. 27, 3609-3620 (2015).

23. Zhang, N. et al. Rechargeable aqueous zinc-manganese dioxide batteries with high energy and power densities. Nat. Commun. 8, 405 (2017).

24. Pan, H. et al. Reversible aqueous zinc/manganese oxide energy storage from conversion reactions. Nat. Energy 1, 16039 (2016).

25. Trócoli, R. \& La Mantia, F. An aqueous zinc-ion battery based on copper hexacyanoferrate. ChemSusChem 8, 481-485 (2015).

26. Zhang, L., Chen, L., Zhou, X. \& Liu, Z. Morphology-dependent electrochemical performance of zinc hexacyanoferrate cathode for zinc-ion battery. Sci. Rep. 5, 18263 (2015).

27. Zhang, L., Chen, L., Zhou, X. \& Liu, Z. Towards high-voltage aqueous metalion batteries beyond $1.5 \mathrm{~V}$ : The zinc/zinc hexacyanoferrate system. $A d v$. Energy Mater. 5, 1400930 (2015).

28. Liu, Z., Pulletikurthi, G. \& Endres, F. A prussian blue/zinc secondary battery with a bio-ionic liquid-water mixture as electrolyte. ACS Appl. Mater. Interfaces 8, 12158-12164 (2016).

29. Chae, M. S., Heo, J. W., Lim, S. C. \& Hong, S. T. Electrochemical zinc-ion intercalation properties and crystal structures of $\mathrm{ZnMo}_{6} \mathrm{~S}_{8}$ and $\mathrm{Zn}_{2} \mathrm{Mo}_{6} \mathrm{~S}_{8}$ chevrel phases in aqueous electrolytes. Inorg. Chem. 55, 3294-3301 (2016).

30. Cheng, Y. et al. Highly reversible zinc-ion intercalation into chevrel phase $\mathrm{Mo}_{6} \mathrm{~S}_{8}$ nanocubes and applications for advanced zinc-ion batteries. ACS Appl. Mater. Interfaces 8, 13673-13677 (2016).

31. Li, G. et al. Towards polyvalent ion batteries: a zinc-ion battery based on NASICON structured $\mathrm{Na}_{3} \mathrm{~V}_{2}\left(\mathrm{PO}_{4}\right)_{3}$. Nano Energy 25, 211-217 (2016).

32. Liu, W. et al. Investigation of zinc ion storage of transition metal oxides, sulfides, and borides in zinc ion batteries system. Chem. Commun. 53, 6872-6874 (2017).

33. Xu, C., Li, B., Du, H. \& Kang, F. Energetic zinc ion chemistry: the rechargeable zinc ion battery. Angew. Chem. Int. Ed. 51, 933-935 (2012).

34. Sun, W. et al. $\mathrm{Zn} / \mathrm{MnO}_{2}$ battery chemistry with $\mathrm{H}^{+}$and $\mathrm{Zn}^{2+}$ coinsertion. $J$. Am. Chem. Soc. 139, 9775-9778 (2017).

35. Cheng, Y. et al. Rechargeable Mg-Li hybrid batteries: status and challenges. J. Mater. Res. 31, 3125-3141 (2016).

36. Gao, T. et al. Enhancing the reversibility of $\mathrm{Mg} / \mathrm{S}$ battery chemistry through $\mathrm{Li}$ + mediation. J. Am. Chem. Soc. 137, 12388-12393 (2015).

37. Wang, H., Wang, W., Ren, Y., Huang, K. \& Liu, S. A new cathode material $\mathrm{Na}_{2} \mathrm{~V}_{6} \mathrm{O}_{16} \cdot \mathrm{xH}_{2} \mathrm{O}$ nanowire for lithium ion battery. J. Power Sources 199, 263-269 (2012).

38. Nguyen, D. et al. Plate-type $\mathrm{NaV}_{3} \mathrm{O}_{8}$ cathode by solid state reaction for sodium-ion batteries. ECS Electrochem. Lett. 3, A69-A71 (2014).

39. Dong, Y. et al. Hierarchical zigzag $\mathrm{Na}_{1.25} \mathrm{~V}_{3} \mathrm{O}_{8}$ nanowires with topotactically encoded superior performance for sodium-ion battery cathodes. Energy Environ. Sci. 8, 1267-1275 (2015).

40. Wang, H., Liu, S., Ren, Y., Wang, W. \& Tang, A. Ultrathin $\mathrm{Na}_{1.08} \mathrm{~V}_{3} \mathrm{O}_{8}$ nanosheets-a novel cathode material with superior rate capability and cycling stability for Li-ion batteries. Energy Environ. Sci. 5, 6173-6179 (2012).

41. Ko, Y. W. et al. Electrospun single-phase $\mathrm{Na}_{1.2} \mathrm{~V}_{3} \mathrm{O}_{8}$ materials with tunable mrphologies as cathodes for rechargeable lithium-ion batteries. ChemElectroChem 2, 837-846 (2015).

42. Reddy Channu, V. S., Holze, R., Yeo, I. H., Mho, Si \& Kalluru, R. R. Electrochemical properties of polyaniline-modified sodium vanadate nanomaterials. Appl. Phys. A 104, 707-711 (2011).

43. Ye, P., Wang, X., Wang, M., Fan, Y. \& Xiang, X. Recovery of vanadium from stone coal acid leaching solution by coprecipitation, alkaline roasting and water leaching. Hydrometallurgy 117, 108-115 (2012).

44. Durupthy, O. et al. Influence of $\mathrm{pH}$ and ionic strength on vanadium(V) oxides formation. From $\mathrm{V}_{2} \mathrm{O}_{5} \cdot \mathrm{nH}_{2} \mathrm{O}$ gels to crystalline $\mathrm{NaV}_{3} \mathrm{O}_{8} \cdot 1.5 \mathrm{H}_{2} \mathrm{O}$. J. Mater. Chem. 15, 1090-1098 (2005).
45. Rui, X. et al. Ambient dissolution-recrystallization towards large-scale preparation of $\mathrm{V}_{2} \mathrm{O}_{5}$ nanobelts for high-energy battery applications. Nano Energy 22, 583-593 (2016).

46. Chithaiah, P., Chandrappa, G. T. \& Livage, J. Formation of crystalline $\mathrm{Na}_{2} \mathrm{~V}_{6} \mathrm{O}_{16} \cdot 3 \mathrm{H}_{2} \mathrm{O}$ ribbons into belts and rings. Inorg. Chem. 51, 2241-2246 (2012).

47. Shirpour, M., Cabana, J. \& Doeff, M. New materials based on a layered sodium titanate for dual electrochemical $\mathrm{Na}$ and $\mathrm{Li}$ intercalation systems. Energy Environ. Sci. 6, 2538-2547 (2013).

48. Kang, $\mathrm{H}$. et al. $\mathrm{NaV}_{3} \mathrm{O}_{8}$ nanosheet@polypyrrole core-shell composites with good electrochemical performance as cathodes for Na-ion batteries. Nanoscale 7, 9261-9267 (2015).

49. Ding, F. et al. Dendrite-free lithium deposition via self-healing electrostatic shield mechanism. J. Am. Chem. Soc. 135, 4450-4456 (2013).

50. Zhang, $\mathrm{X}$. H. et al. $\mathrm{P} 2-\mathrm{Na}_{2 / 3} \mathrm{Ni}_{1 / 3} \mathrm{Mn}_{5 / 9} \mathrm{Al}_{1 / 9} \mathrm{O}_{2}$ microparticles as superior cathode material for sodium-ion batteries: enhanced properties and mechanisam via graphene connection. ACS Appl. Mater. Interfaces 8, 20650-20659 (2016).

51. He, G., Bridges, C. A. \& Manthiram, A. Crystal chemistry of electrochemically and chemically lithiated layered $\alpha_{\mathrm{I}}$ LiVOPO $_{4}$. Chem. Mater. 27, 6699-6707 (2015).

52. Kim, J.-H. et al. Integrated nano-domains of disordered and ordered spinel phases in $\mathrm{LiNi}_{0.5} \mathrm{Mn}_{1.5} \mathrm{O}_{4}$ for Li-Ion batteries. Chem. Mater. 26, 4377-4386 (2014).

53. Zhang, K. et al. Urchin-like $\mathrm{CoSe}_{2}$ as a high-performance anode material for sodium-ion batteries. Adv. Funct. Mater. 26, 6728-6735 (2016).

54. Chao, D. et al. Array of nanosheets render ultrafast and high-capacity Na-ion storage by tunable pseudocapacitance. Nat. Commun. 7, 12122 (2016).

55. Chao, D. et al. Pseudocapacitive Na-ion storage boosts high rate and areal capacity of self-branched 2D layered metal chalcogenide nanoarrays. ACS Nano 10, 10211-10219 (2016).

56. Xia, X. et al. Generic synthesis of carbon nanotube branches on metal oxide arrays exhibiting stable high-rate and long-cycle sodium-ion storage. Small $\mathbf{1 2}$ 3048-3058 (2016)

57. Luo, J.-Y., Cui, W.-J., He, P. \& Xia, Y.-Y. Raising the cycling stability of aqueous lithium-ion batteries by eliminating oxygen in the electrolyte. Nat. Chem. 2, 760-765 (2010)

58. Shan, X. et al. Bivalence $\mathrm{Mn}_{5} \mathrm{O}_{8}$ with hydroxylated interphase for high-voltage aqueous sodium-ion storage. Nat. Commun. 7, 13370 (2016).

59. Suo, L. et al. "Water-in-salt" electrolyte enables high-voltage aqueous lithiumion chemistries. Science 350, 938-943 (2015).

60. Qu, Q., Li, L., Bai, W. \& Yan, Cw Initial atmospheric corrosion of zinc in presence of $\mathrm{Na}_{2} \mathrm{SO}_{4}$ and $\left(\mathrm{NH}_{4}\right)_{2} \mathrm{SO}_{4}$. Trans. Nonferrous Metals Soc. China 16, 887-891 (2006).

61. Hiralal, P. et al. Nanomaterial-enhanced all-solid flexible zinc-carbon batteries. ACS Nano 4, 2730-2734 (2010)

62. Niu, Z. et al. All-solid-state flexible ultrathin micro-supercapacitors based on graphene. Adv. Mater. 25, 4035-4042 (2013).

63. Cao, J. et al. A flexible nanostructured paper of a reduced graphene oxidesulfur composite for high-performance lithium-sulfur batteries with unconventional configurations. Adv. Mater. 28, 9629-9636 (2016).

64. Chen, C. et al. Foldable all-solid-state supercapacitors integrated with photodetectors. Adv. Funct. Mater. 27, 1604639 (2016).

65. Zhao, J. et al. A smart flexible zinc battery with cooling recovery ability. Angew. Chem. Int. Ed. 129, 7979-7983 (2017)

66. Zeng, Y. et al. Achieving ultrahigh energy density and long durability in a flexible rechargeable quasi-solid-state $\mathrm{Zn}-\mathrm{MnO}_{2}$ battery. Adv. Mater. 29, 1700274 (2017)

67. Huang, W. et al. Quasi-solid-state rechargeable lithium-ion batteries with a Calix[4]quinone cathode and gel polymer electrolyte. Angew. Chem. Int. Ed. 52, 9162-9166 (2013).

68. $\mathrm{Hu}, \mathrm{X}$. et al. Quasi-solid state rechargeable $\mathrm{Na}-\mathrm{CO}_{2}$ batteries with reduced graphene oxide Na anodes. Sci. Adv. 3, e1602396 (2017).

69. Liu, Z. et al. Dendrite-free nanocrystalline zinc electrodeposition from an ionic liquid containing nickel triflate for rechargeable $\mathrm{Zn}$-based batteries. Angew. Chem. Int. Ed. 55, 2889-2893 (2016).

\section{Acknowledgements}

This work was supported by MOST (2017YFA0206701), National Natural Science Foundation of China (21573116 and 51602218), Ministry of Education of China (B12015), and Tianjin Basic and High-Tech Development (15JCYBJC17300). Z.N. thanks the Young Thousand Talents Program.

\section{Author contributions}

J.C., Z.N., and F.W. conceived the idea. F.W. performed the experiments. L.Z. and X.D. contributed to electrochemical measurement. X.W. assisted in packaging the flexible 
quasi-solid-state batteries. J.C., Z.N., and F.W. wrote the paper. All authors took part in the result discussion and data analysis.

\section{Additional information}

Supplementary Information accompanies this paper at https://doi.org/10.1038/s41467018-04060-8.

Competing interests: The authors declare no competing interests.

Reprints and permission information is available online at http://npg.nature.com/ reprintsandpermissions/

Publisher's note: Springer Nature remains neutral with regard to jurisdictional claims in published maps and institutional affiliations. (c) (i) Open Access This article is licensed under a Creative Commons Attribution 4.0 International License, which permits use, sharing, adaptation, distribution and reproduction in any medium or format, as long as you give appropriate credit to the original author(s) and the source, provide a link to the Creative Commons license, and indicate if changes were made. The images or other third party material in this article are included in the article's Creative Commons license, unless indicated otherwise in a credit line to the material. If material is not included in the article's Creative Commons license and your intended use is not permitted by statutory regulation or exceeds the permitted use, you will need to obtain permission directly from the copyright holder. To view a copy of this license, visit http://creativecommons.org/ licenses/by/4.0/.

(C) The Author(s) 2018 